\title{
Nitroacetylene as dipolarophile in $[2+3]$ cycloaddition reactions with allenyl-type three-atom components: DFT computational study
}

\author{
Radomir Jasiński
}

Received: 24 October 2014/Accepted: 15 December 2014/Published online: 27 January 2015

(C) The Author(s) 2015. This article is published with open access at Springerlink.com

\begin{abstract}
Cycloaddition reactions of nitroacetylene with allenyl-type three-atom components take place according to the polar, but a one-step mechanism. Alternatively to cycloadducts, during the reaction between the aforementioned reagents, zwitterionic structures with "extended" conformation may be formally created. However, this route is supported by neither kinetic nor thermodynamic factors.
\end{abstract}

\section{Graphical Abstract}

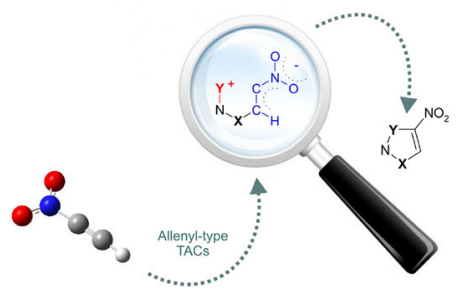

Keywords Cycloaddition - Mechanism .

Regioselectivity · DFT study

\section{Introduction}

Nitroacetylenes belong-because of the presence of a strongly electron withdrawing $\mathrm{NO}_{2}$-group-to a class of strongly electrophilic acetylenes. They are relatively

R. Jasiński ( $\square)$

Institute of Organic Chemistry and Technology, Cracow

University of Technology, Cracow, Poland

e-mail: radomir@chemia.pk.edu.pl unstable, and their physicochemistry is very poorly known [1].

In particular, very little is known about the simple representative of this group of compounds-parent nitroacetylene (1). Recently, the preliminary results of experimental studies related to nitroacetylene as a DielsAlder reaction component were published [2]. However, no systematic studies of its participation in reactions of $[2+3]$ cycloaddition have been performed to date. This work initiates research in this area; in particular, within the study, complex, quantum-chemical studies of the $[2+3]$ cycloaddition reaction of nitroacetylene (1) to selected allenyl-type three-atom components (TACs). Three such TACs were selected, often tested in recent years as components of $[2+3]$ cycloaddition reactions with electrophilic ethylenes: benzonitrile $N$-oxide (2a) [3-6], phenyl azide (2b) [6-8], and phenyldiazomethane (2c) $[6,9]$ (Scheme 1).

Reactions of these TACs with nitroacetylene are a potentially highly effective and selective method of synthesis of nitro-substituted, five-membered, unsaturated heterocycles that are valuable from the point of view of organic preparatory work [10-12]. For this reason, identification of factors determining their course is so important. With this in mind, the following work was performed: (1) an analysis of nature of reagent interactions based on reactivity indices theory, and (2) simulations of a theoretically possible reaction path in the presence of a weakly polar (toluene), and strongly polar medium (nitromethane). It must be stressed here that the problematics of the [2+3] cycloaddition reaction of the aforementioned reagents is also very interesting from a mechanistic point of view. These reactions may also take place according to a onestep mechanism, as well as to a two-step mechanism, with a zwitterionic intermediate [13-15]. The two-step 


\section{Scheme 1}

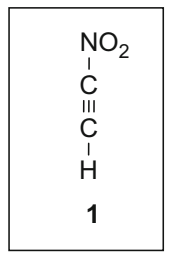

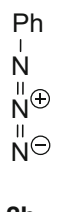

$2 b$
$\mathrm{Ph}$

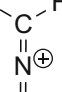

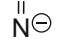

2c

mechanism is facilitated in this case by (1) the strongly electrophilic character of the dipolarophile and the nucleophilic nature of the TACs and (2) unequal screening of the reaction centres of both reagents.

\section{Results and discussion}

Nitroacetylene (1) is characterized by high global electrophilicity [16, 17], exceeding $3 \mathrm{eV}$. Using the scale proposed by Domingo [17], it should be classified as belonging to the group of strong electrophiles. On the other hand, TACs 2a-2c have a significantly weaker electrophilic nature $(\omega<1.6 \mathrm{eV})$ - using the aforementioned scale they are classified as moderate electrophiles. Thus, they should behave as nucleophiles in reactions with nitroacetylene. The nucleophilic character of these compounds is indicated by values of the $N$ indices. As can be concluded from the data summarized in Table 1, phenzyldiazomethane (2c) is the strongest nucleophile in the analysed series, while benzonitrile $N$-oxide (2a) is the weakest nucleophile. It should be noted that in cases of all reagent pairs, the difference in global electrophilicities exceeds $1.5 \mathrm{~V}$. The title reactions are thus polar processes [18].

Next, it was decided to determine which of the theoretically possible directions of substrate transformations would be favoured by the electrophile-nucleophile interactions. In the case of every single one of the cycloaddition reactions studied, two regioisomeric reaction paths can be studied (Scheme 2A, B).

Analysis of local electronic properties allows one to state that the most electrophilically activated centre of the nitroacetylene molecule is the $\mathrm{C}_{\beta}$ carbon atom. Local electrophilicity on the $\mathrm{C}_{\alpha}$ carbon atom is more than three times weaker. On the other hand, the terminal $\mathrm{X}$ atom of TACs is the most nucleophilic activated centre in these species. If it is assumed that the reaction route is determined by an attack of the more strongly nucleophilic reaction centre of the TAC on the more strongly electrophilic reaction centre of nitroacetylene, then the favoured direction of reagent transformation should always be determined by the A path (see Scheme 2).

\section{Reaction profiles}

Taking into account the nature of the electrophile-nucleophile interactions, reactions of nitroacetylene with TACs 2a-2c must be recognized as polar processes. This, however, does not determine their mechanism. There are two possible variants of the conversion of reagents into adducts: (a) a one-step polar mechanism and (b) two-step zwitterionic mechanism. In the first case, one should expect a transition state (TS) in the energy profile, in the second two TSs connected by a valley corresponding to the zwitterionic intermediate (respectively, $\mathbf{5}$ or $\mathbf{6}$, see Scheme 2).

As suggested by quantum-chemical calculations, in weakly polar toluene $(\varepsilon=2.38)$, the reaction of nitroacetylene with benzonitrile $N$-oxide takes placeregardless of the regioisomeric path-as a one-step process. All attempts at finding paths leading to zwitterionic structures ended unsuccessfully.

Formation of a pre-reaction complex (local minimumLM) always comprises the first reaction step. This is related to a certain drop in enthalpy of the reacting system. It should be noted, that LMs are exclusively enthalpic in character because Gibbs free energy gap between suitable intermediate and reactants is always greater than zero $(\Delta G>0)$ due to the entropic factor $(T \Delta S)$. Therefore, prereaction complexes may not exist as stable products.

Only then does the system start heading towards the activation barrier. By analysing barrier heights on paths $\mathbf{A}$ and $\mathbf{B}$, it must be said that both regioisomeric substrate

Table 1 Essential electronic properties of nitroacetylene (1) and TACs $\mathbf{2 a - 2 c}$

\begin{tabular}{|c|c|c|c|c|c|c|c|c|c|c|c|}
\hline & \multicolumn{3}{|c|}{ Global properties } & \multicolumn{8}{|c|}{ Local properties } \\
\hline & $\mu /$ a.u. & $\omega / \mathrm{eV}$ & $\mathrm{N} / \mathrm{eV}$ & $P_{\mathrm{X}}^{-}$ & $P_{\mathrm{Y}}^{-}$ & $N_{\mathrm{X}} / \mathrm{eV}$ & $N_{\mathrm{Y}} / \mathrm{eV}$ & $P_{\alpha}^{+}$ & $P_{\beta}^{+}$ & $\omega_{\alpha} / \mathrm{eV}$ & $\omega_{\beta} / \mathrm{eV}$ \\
\hline 1 & -0.1771 & 3.14 & & & & & & -0.10 & 0.33 & -0.30 & 1.05 \\
\hline $2 \mathbf{a}$ & -0.1406 & 1.46 & 2.78 & 0.42 & 0.01 & 1.18 & 0.03 & & & & \\
\hline $2 \mathbf{b}$ & -0.1330 & 1.27 & 2.92 & 0.21 & 0.19 & 0.60 & 0.57 & & & & \\
\hline $2 c$ & -0.1276 & 1.55 & 3.71 & 0.34 & 0.25 & 1.26 & 0.94 & & & & \\
\hline
\end{tabular}


Scheme 2

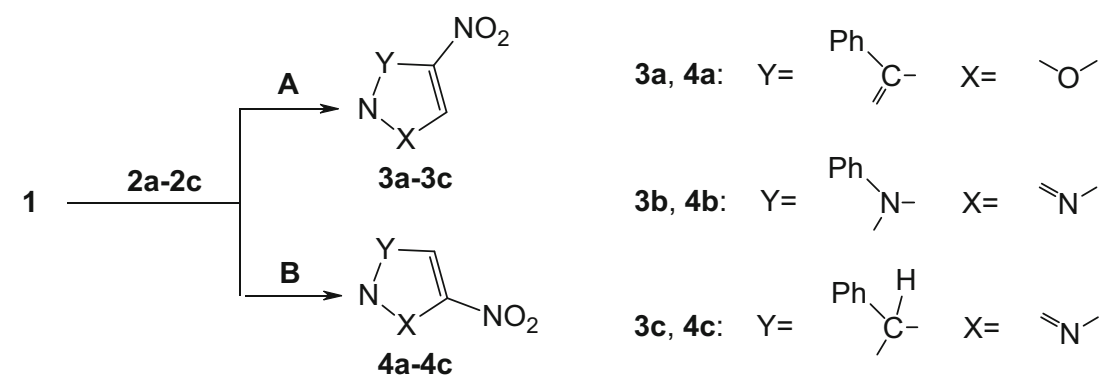

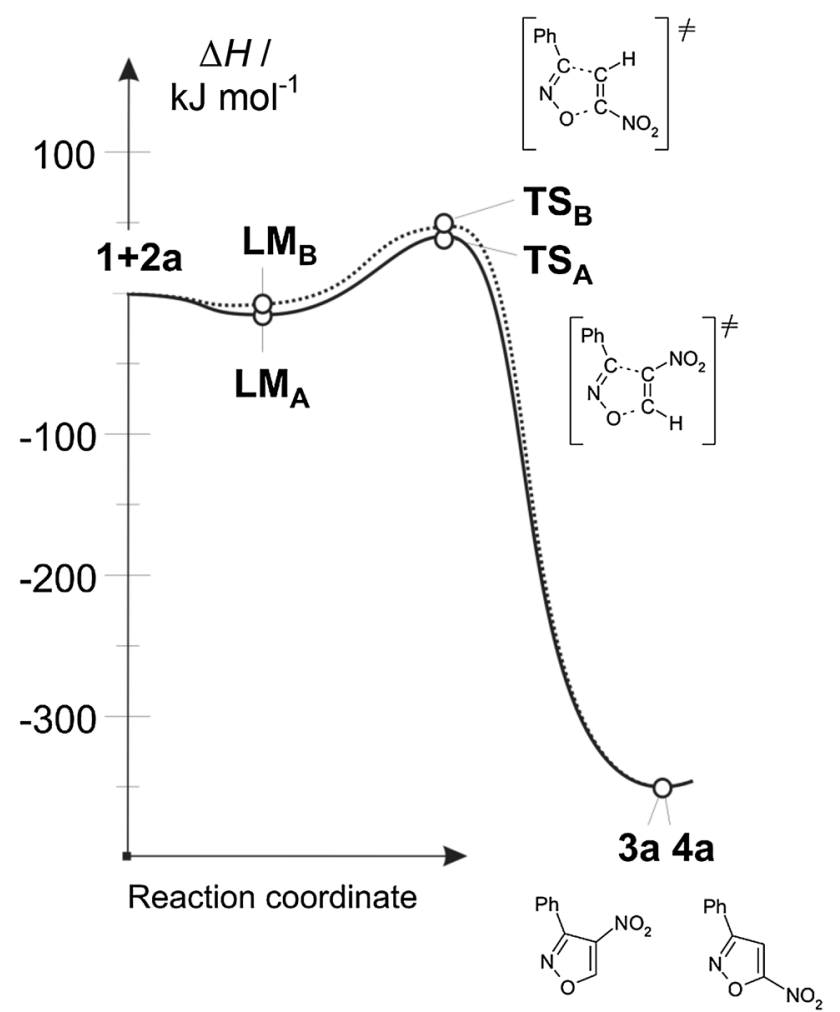

Fig. 1 Enthalpy profiles for reaction between nitroacetylene (1) and benzonitrile $N$-oxide (2a) in toluene according to DFT calculations at B3LYP/6-31G(d) theory level

transformation routes are possible from the kinetic point of view. However, the favoured path is the one leading finally to 4-nitroisoxazole (3a). This conclusion is in agreement with forecasts based on reactivity indices analysis.

A similar picture of $\mathbf{1}+\mathbf{2 a}$ reaction is provided by calculations at more advanced levels of theory B3LYP/6-31+G(d), B3LYP/6-311G(d), and B3LYP/6-311+G(d) (Fig. 1).

DFT calculations also indicate a one-step mechanism of cycloaddition reaction of nitroacetylene to TACs $\mathbf{2 b}$ and 2c. The performed simulations suggest, however, a different reaction regioselectivity than would result from reactivity index analysis. In particular, in the case of cycloaddition reactions using phenyl azide (2b), both regioisomeric reaction channels should be permitted, but path $\mathbf{B}$ will be favoured. However, in the case of a cycloaddition reaction using phenyldiazomethane, path $\mathbf{A}$ must be treated as kinetically forbidden. DFT calculations indicate that the only permitted cycloaddition channel is the path leading to the $\mathbf{4} \mathbf{c}$ adduct.

Analysing conversion routes for reagent pairs $\mathbf{1}+\mathbf{2 b}$, paths leading to zwitterionic structures were found (Fig. 2). However, these are not the expected zwitterions 5 and $\mathbf{6}$ with "cyclic" conformation (see. Scheme 3) but zwitterions with "extended" conformation $\mathbf{7}$ and $\mathbf{8}$ (see Scheme 4). Their conversion to adducts can be executed via a step of dissociation into individual reagents and (in the next step) a stage of cycloaddition according to a one-step mechanism. These paths should be treated as formally forbidden from the kinetic point of view. Thermodynamic factors also do not favour formation of zwitterions $\mathbf{7}$ and $\mathbf{8}$.

Introduction of a more polar medium of nitromethane $(\varepsilon=38.20)$ into the reaction mixture does not result in qualitative changes in energy profiles of the reaction. However, their quantitative description does change. In particular, activation barriers in cases of relatively less polar cycloaddition reactions $\mathbf{1}+\mathbf{2 a} \rightarrow \mathbf{3 a} / \mathbf{4 a}$ and $1+2 b \rightarrow 3 b / 4 b$ increase. In case of the most polar of the considered cycloaddition reactions $(1+\mathbf{2 c} \rightarrow \mathbf{3 c} / \mathbf{4 c})$, activation barriers become slightly lower in a more polar medium. However, in the case of all reactions leading to zwitterions $\mathbf{7}$ and $\mathbf{8}$ an increase in the polarity of the reaction medium facilitates the lowering of the activation barrier. However, this lowering is not significant enough to treat these processes as permitted kinetically.

\section{Key structures}

Within the area of located pre-reaction complexes LM distances between reaction centres still remain far outside the range typical for $\sigma$ bonds in intermediate states. Some LMs are orientation complexes. None of them has, however-regardless of reaction medium polarity-the nature 
Fig. 2 Enthalpy profiles for reaction between nitroacetylene (1) and phenylazide (2b) in toluene according to DFT calculations at B3LYP/6-

$31 \mathrm{G}(\mathrm{d})$ theory level

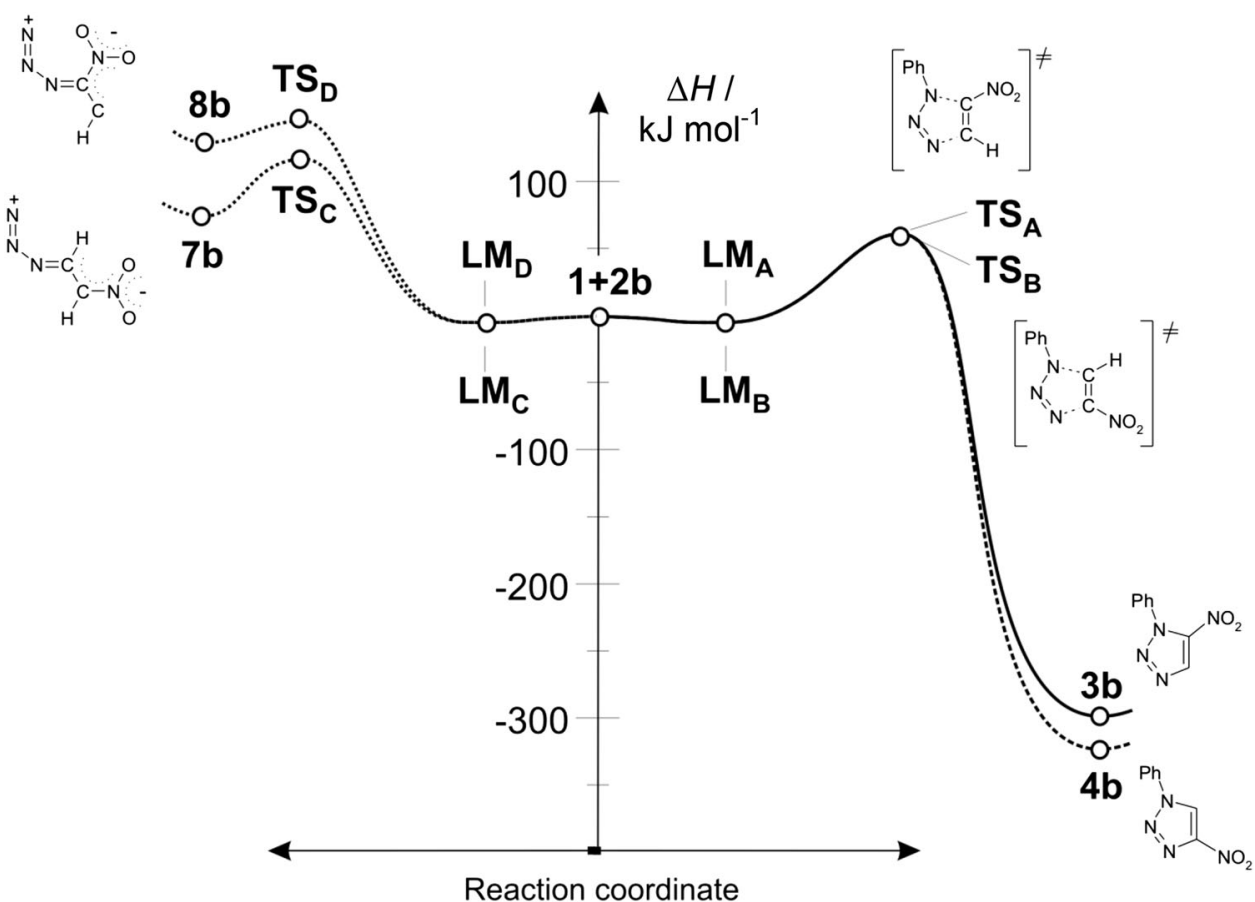

Scheme 3 of a charge-transfer complex (CT) [see global electron density transfer indices (GEDT) in Table 2].

New $\sigma$ bonds are formed after the system reaches the TS. Analysing geometrical parameters of TS leading to cycloadducts 3 and 4, it can be noted that the advancement stage of new bonds depends on reagent nature and-to a smaller extent-on medium polarity.

So, in the case of a reaction with benzonitrile $N$-oxide in toluene, the bond at the $\beta$ carbon atom introduced from nitroacetylene always is more advanced at the TS (Fig. 3). Formation of bonds in the area of the less favoured energetically $\mathrm{TS}_{\mathrm{B}}$ takes place in a more asynchronous manner $(\Delta l>0.2)$. Both TSs have a polar nature, which is reflected in the value of GEDT index (see Table 2).

In case of a similar reaction with phenyl azide in the same reaction medium, both analysed TSs show a similar level of asynchronicity. The more energetically favourable $\mathrm{TS}_{\mathrm{B}}$ is the more polar one of the two.

On the other hand, the nature of TSs of the reaction using phenyldiazomethane shows complete difference. In particular, the less energetically favourable $\mathrm{TS}_{\mathrm{A}}$ is characterized by an almost ideal synchronicity of new $\sigma$ bond 


\section{Scheme 4}

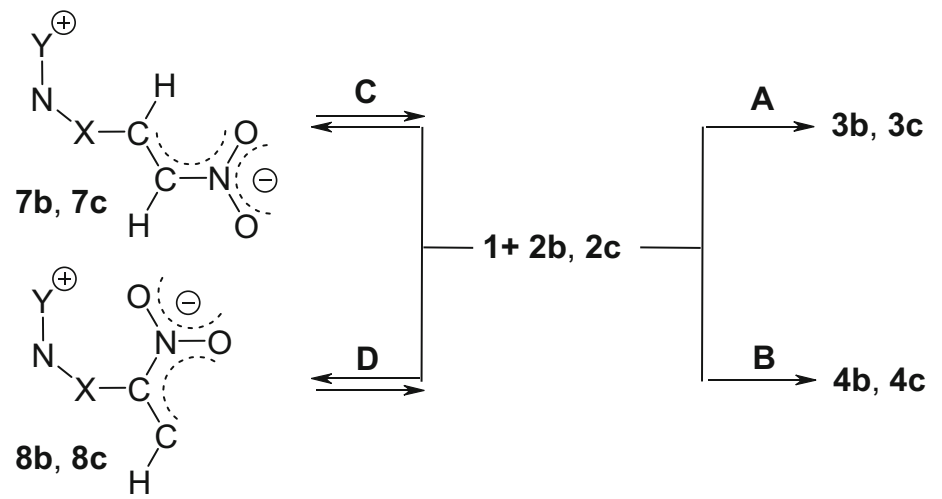

Table 2 Selected properties of critical structures for reactions between nitroacetylene (1) and TACs $\mathbf{2 a - 2 c}$ according to B3LYP/6-31G(d) calculations

\begin{tabular}{|c|c|c|c|c|c|c|c|c|c|c|c|c|}
\hline \multirow[t]{3}{*}{ Solvent } & \multirow[t]{3}{*}{ Reaction } & \multirow[t]{3}{*}{ Structure } & \multicolumn{8}{|c|}{ Interatomic distances } & \multirow[t]{3}{*}{$\Delta l$} & \multirow[t]{3}{*}{ GEDT/e } \\
\hline & & & \multicolumn{2}{|l|}{$\mathrm{X}-\mathrm{C}_{\alpha}$} & \multicolumn{2}{|l|}{$\mathrm{X}-\mathrm{C}_{\beta}$} & \multicolumn{2}{|l|}{$\mathrm{Y}-\mathrm{C}_{\alpha}$} & \multicolumn{2}{|l|}{$\mathrm{Y}-\mathrm{C}_{\beta}$} & & \\
\hline & & & $\overrightarrow{r l \AA}$ & $l$ & $\overrightarrow{r / \AA}$ & $l$ & 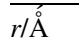 & $l$ & $\overline{r l \AA}$ & $l$ & & \\
\hline \multirow[t]{27}{*}{ Toluene $(\varepsilon=2.38)$} & $1+2 a$ & $\mathbf{L M}_{\mathbf{A}}$ & & & 3.103 & & 4.246 & & & & & \\
\hline & & $\mathbf{T S}_{\mathrm{A}}$ & & & 2.130 & 0.392 & 2.392 & 0.340 & & & 0.05 & 0.11 \\
\hline & & $\mathbf{3 a}$ & & & 1.325 & & 1.441 & & & & & \\
\hline & & $\mathbf{L M}_{\mathbf{B}}$ & 3.328 & & & & & & 5.598 & & & \\
\hline & & $\mathbf{T S}_{\mathbf{B}}$ & 2.321 & 0.248 & & & & & 2.219 & 0.460 & 0.21 & 0.11 \\
\hline & & $4 a$ & 1.325 & & & & & & 1.441 & & & \\
\hline & $\mathbf{1}+\mathbf{2 b}$ & $\mathbf{L M}_{\mathbf{A}}$ & & & 1.441 & & 1.441 & & & & & \\
\hline & & $\mathbf{T S}_{\mathbf{A}}$ & & & 2.117 & 0.433 & 2.241 & 0.361 & & & 0.07 & 0.05 \\
\hline & & $\mathbf{3 b}$ & & & 1.351 & & 1.367 & & & & & \\
\hline & & $\mathbf{L M}_{\mathbf{B}}$ & 4.223 & & & & & & 7.214 & & & \\
\hline & & $\mathbf{T S}_{\mathbf{B}}$ & 2.279 & 0.317 & & & & & 2.131 & 0.421 & 0.10 & 0.08 \\
\hline & & $4 b$ & 1.354 & & & & & & 1.350 & & & \\
\hline & & $\mathbf{L} \mathbf{M}_{\mathbf{C}}$ & & & 4.741 & & & & & & & \\
\hline & & $\mathbf{T S}_{\mathbf{C}}$ & & & 1.728 & 0.699 & & & & & & 0.26 \\
\hline & & $7 b$ & & & 1.329 & & & & & & & \\
\hline & & $\mathbf{L} \mathbf{M}_{\mathbf{D}}$ & 3.507 & & & & & & & & & \\
\hline & & $\mathbf{T S}_{\mathbf{D}}$ & 1.549 & 0.880 & & & & & & & & 0.21 \\
\hline & & $8 b$ & 1.383 & & & & & & & & & \\
\hline & $1+2 c$ & $\mathbf{L M}_{\mathbf{A}}$ & & & 4.106 & & 3.872 & & & & & \\
\hline & & $\mathbf{T S}_{\mathbf{A}}$ & & & 2.285 & 0.401 & 2.335 & 0.438 & & & 0.04 & 0.20 \\
\hline & & $3 c$ & & & 1.429 & & 1.495 & & & & & \\
\hline & & $\mathbf{T S}_{\mathbf{B}}$ & 2.513 & 0.237 & & & & & 2.220 & 0.513 & 0.28 & 0.21 \\
\hline & & $4 c$ & 1.426 & & & & & & 1.493 & & & \\
\hline & & $\mathbf{T S}_{\mathbf{C}}$ & & & 1.845 & 0.619 & & & & & & 0.28 \\
\hline & & $7 c$ & & & 1.336 & & & & & & & \\
\hline & & $\mathbf{T S}_{\mathbf{D}}$ & 1.623 & 0.798 & & & & & & & & 0.36 \\
\hline & & $8 c$ & 1.350 & & & & & & & & & \\
\hline
\end{tabular}


Table 2 continued

\begin{tabular}{|c|c|c|c|c|c|c|c|c|c|c|c|c|}
\hline \multirow[t]{3}{*}{ Solvent } & \multirow[t]{3}{*}{ Reaction } & \multirow[t]{3}{*}{ Structure } & \multicolumn{8}{|c|}{ Interatomic distances } & \multirow[t]{3}{*}{$\Delta l$} & \multirow[t]{3}{*}{ GEDT/e } \\
\hline & & & \multicolumn{2}{|l|}{$\mathrm{X}-\mathrm{C}_{\alpha}$} & \multicolumn{2}{|l|}{$\mathrm{X}-\mathrm{C}_{\beta}$} & \multicolumn{2}{|l|}{$\mathrm{Y}-\mathrm{C}_{\alpha}$} & \multicolumn{2}{|l|}{$\mathrm{Y}-\mathrm{C}_{\beta}$} & & \\
\hline & & & $r / \AA$ & $l$ & $r / \AA$ & $l$ & $r / \AA$ & $l$ & $r / \AA$ & $l$ & & \\
\hline \multirow[t]{27}{*}{ Nitromethane $(\varepsilon=38.20)$} & $\mathbf{1}+\mathbf{2 a}$ & $\mathbf{L M}_{\mathbf{A}}$ & & & 3.122 & & 4.287 & & & & & \\
\hline & & $\mathbf{T S}_{\mathbf{A}}$ & & & 2.106 & 0.410 & 2.409 & 0.326 & & & 0.08 & 0.13 \\
\hline & & $\mathbf{3 a}$ & & & 1.324 & & 1.439 & & & & & \\
\hline & & $\mathbf{L M}_{\mathbf{B}}$ & 3.396 & & & & & & 5.636 & & & \\
\hline & & $\mathbf{T S}_{\mathbf{B}}$ & 2.320 & 0.268 & & & & & 2.204 & 0.459 & 0.19 & 0.12 \\
\hline & & $4 a$ & 1.339 & & & & & & 1.431 & & & \\
\hline & $\mathbf{1}+\mathbf{2 b}$ & $\mathbf{L M}_{\mathbf{A}}$ & & & 5.770 & & 4.195 & & & & & \\
\hline & & $\mathbf{T S}_{\mathbf{A}}$ & & & 2.103 & 0.443 & 2.248 & 0.354 & & & 0.09 & 0.07 \\
\hline & & $3 \mathbf{b}$ & & & 1.351 & & 1.366 & & & & & \\
\hline & & $\mathbf{L M}_{\mathbf{B}}$ & 3.306 & & & & & & 5.770 & & & \\
\hline & & $\mathbf{T S}_{\mathbf{B}}$ & 2.312 & 0.294 & & & & & 2.106 & 0.438 & 0.14 & 0.10 \\
\hline & & $4 b$ & 1.355 & & & & & & 1.348 & & & \\
\hline & & $\mathbf{L M}_{\mathbf{C}}$ & & & 4.675 & & & & & & & \\
\hline & & $\mathbf{T S}_{\mathbf{C}}$ & & & 1.777 & 0.702 & & & & & & 0.29 \\
\hline & & $7 \mathrm{~b}$ & & & 1.369 & & & & & & & 0.29 \\
\hline & & $\mathbf{L M}_{\mathrm{D}}$ & 3.615 & & & & & & & & & \\
\hline & & $\mathbf{T S}_{\mathbf{D}}$ & 1.561 & 0.880 & & & & & & & & 0.33 \\
\hline & & $8 b$ & 1.394 & & & & & & & & & 0.32 \\
\hline & $1+2 c$ & $\mathbf{L} \mathbf{M}_{\mathbf{A}}$ & & & 5.441 & & 8.076 & & & & & \\
\hline & & $\mathbf{T S}_{\mathbf{A}}$ & & & 2.219 & 0.446 & 2.388 & 0.401 & & & 0.04 & 0.21 \\
\hline & & $3 c$ & & & 1.428 & & 1.494 & & & & & \\
\hline & & $\mathbf{T S}_{\mathbf{B}}$ & 2.596 & 0.176 & & & & & 2.200 & 0.526 & 0.35 & 0.27 \\
\hline & & $4 c$ & 1.424 & & & & & & 1.492 & & & \\
\hline & & $\mathbf{T S}_{\mathbf{C}}$ & & & 1.915 & 0.585 & & & & & & 0.30 \\
\hline & & $7 c$ & & & 1.353 & & & & & & & 0.25 \\
\hline & & $\mathbf{T S}_{\mathrm{D}}$ & 1.621 & 0.819 & & & & & & & & 0.40 \\
\hline & & $8 c$ & 1.373 & & & & & & & & & 0.31 \\
\hline
\end{tabular}
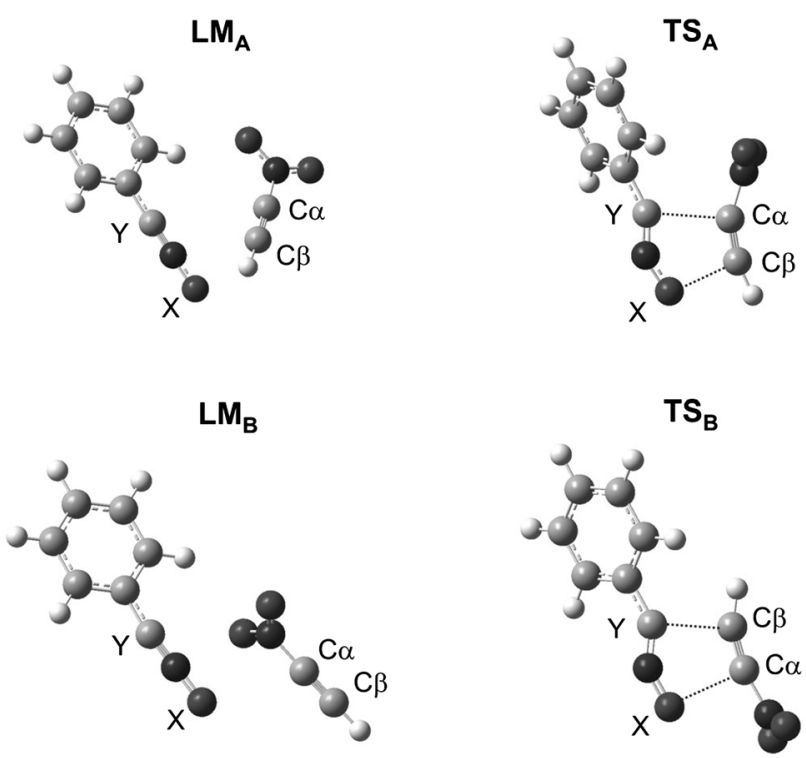

Fig. 3 Key structures for reaction between nitroacetylene (1) and benzonitrile $N$-oxide (2a) in toluene according to DFT calculations at B3LYP/6-31G(d) theory level formation and a very weak polar character. On the other hand, in the area of $\mathrm{TS}_{\mathrm{B}}$ new $\sigma$ bonds are formed in a strongly asynchronous manner, accompanied by a strong charge-transfer effect towards the dipolarophile substructure. The asynchronicity of this TS is the greatest among all considered critical structures.

With the introduction of a stronger polar medium of nitromethane into the reaction medium, key parameters of the analysed structures do not change significantly. In the area of most TSs, asynchronicity of formation of new $\sigma$ bonds increases. However, it does not increase enough to enforce a change in reaction mechanism.

Within TSs on paths $\mathbf{C}$ and $\mathbf{D}$ only one bond is always formed. It is always the bond with the more nucleophilic atom of the X 1,3-dipole (Fig. 3). Progress of this bond is always greater than $50 \%$ (see $l$ values in Table 2). It should be noted that TSs on paths leading to zwitterions 7 and $\mathbf{8}$ are always more polar than competitive units on paths leading to cycloadducts $\mathbf{3}$ and $\mathbf{4}$. Also in the case of these structures, the polarity increase of the reaction 
medium does not change their nature substantially. Only their polarity becomes more pronounced (see GEDT values In Table 2).

\section{Conclusion}

DFT calculations for various theory levels show that $[2+3]$ cycloaddition reactions of nitroacetylene with allenyl-type TACs take place according to the polar mechanism. This is not, however, the expected two-step, zwitterionic mechanism, but a one-step mechanism. Zwitterionic structures with the "extended" conformation may theoretically form along competitive paths. However, this route is supported by neither kinetic nor thermodynamic factors. Despite the clearly polar nature of the reactions discussed, the influence of the polarity of the reaction medium on their kinetics and the nature of critical structures is relatively small.

\section{Computational details}

All calculations reported in this paper were performed on "Zeus" supercomputer in the "Cyfronet" computational centre in Cracow.

Global and local electronic properties of reactants were estimated according to the equations described earlier. In particular, the electronic chemical potentials $(\mu)$ and chemical hardness $(\eta)$ were evaluated in terms of oneelectron energies of FMO ( $E_{\mathrm{HOMO}}$ and $\left.E_{\mathrm{LUMO}}\right)$ using the equations:

Table 3 Eyring parameters for reactions between nitroacetylene (1) and TACs 2a-2c according to B3LYP/6-31G(d) calculations

\begin{tabular}{|c|c|c|c|c|c|c|c|}
\hline \multirow[t]{2}{*}{ 1,3-Dipole } & \multirow[t]{2}{*}{ Transition } & \multicolumn{3}{|c|}{ Toluene $(\varepsilon=2.38)$} & \multicolumn{3}{|c|}{ Nitromethane $(\varepsilon=38.20)$} \\
\hline & & $\Delta H / \mathrm{kJ} \mathrm{mol}^{-1}$ & $\Delta G / \mathrm{kJ} \mathrm{mol}^{-1}$ & $\Delta S / \mathrm{J} \mathrm{mol}^{-1} \mathrm{~K}^{-1}$ & $\Delta H / \mathrm{kJ} \mathrm{mol}^{-1}$ & $\Delta G / \mathrm{kJ} \mathrm{mol}^{-1}$ & $\Delta S / \mathrm{J} \mathrm{mol}^{-1} \mathrm{~K}^{-1}$ \\
\hline \multirow[t]{6}{*}{$2 \mathbf{a}$} & $\mathbf{1}+\mathbf{2} \mathbf{a} \rightarrow \mathbf{L} \mathbf{M}_{\mathbf{A}}$ & -13.8 & 21.8 & -119.2 & -7.1 & 26.4 & -112.1 \\
\hline & $\mathbf{1}+\mathbf{2 a} \rightarrow \mathbf{T S}_{\mathbf{A}}$ & 41.4 & 92.9 & -172.4 & 45.6 & 95.0 & -166.5 \\
\hline & $\mathbf{1}+\mathbf{2 a} \rightarrow \mathbf{3 a}$ & -351.5 & -287.4 & -214.2 & -347.7 & -284.5 & -212.1 \\
\hline & $\mathbf{1}+\mathbf{2} \mathbf{a} \rightarrow \mathbf{L M}_{\mathbf{B}}$ & -7.9 & 28.5 & -122.2 & -4.2 & 30.5 & -117.2 \\
\hline & $\mathbf{1}+\mathbf{2 a} \rightarrow \mathbf{T S}_{\mathbf{B}}$ & 46.0 & 95.8 & -167.4 & 46.4 & 96.2 & -166.9 \\
\hline & $1+2 a \rightarrow 4 a$ & -348.9 & -287.9 & -204.6 & -347.3 & -278.2 & -231.4 \\
\hline \multirow[t]{12}{*}{$2 \mathbf{b}$} & $\mathbf{1}+\mathbf{2 b} \rightarrow \mathbf{L} \mathbf{M}_{\mathbf{A}}$ & -2.9 & 24.3 & -92.0 & -1.7 & 24.3 & -86.2 \\
\hline & $\mathbf{1}+\mathbf{2 b} \rightarrow \mathbf{T S}_{\mathrm{A}}$ & 59.4 & 109.6 & -168.2 & 61.5 & 111.7 & -168.6 \\
\hline & $1+2 b \rightarrow 3 b$ & -298.7 & -238.1 & -202.5 & -299.6 & -239.3 & -202.1 \\
\hline & $\mathbf{1}+\mathbf{2 b} \rightarrow \mathbf{L M}_{\mathbf{B}}$ & -5.0 & 23.0 & -94.6 & -2.9 & 26.4 & -98.3 \\
\hline & $1+2 \mathbf{b} \rightarrow \mathbf{T S}_{\mathbf{B}}$ & 59.0 & 108.4 & -164.8 & 58.2 & 107.1 & -164.8 \\
\hline & $1+2 b \rightarrow 4 b$ & -327.2 & -266.1 & -205.4 & -332.2 & -271.5 & -204.6 \\
\hline & $\mathbf{1}+\mathbf{2 b} \rightarrow \mathbf{L} \mathbf{M}_{\mathbf{C}}$ & -5.4 & 21.8 & -91.6 & -2.9 & 23.0 & -87.0 \\
\hline & $\mathbf{1}+\mathbf{2 b} \rightarrow \mathbf{T S}_{\mathbf{C}}$ & 125.1 & 169.9 & -150.2 & 111.3 & 157.7 & -155.6 \\
\hline & $1+2 b \rightarrow 7 b$ & 72.8 & 120.5 & -160.7 & 66.1 & 114.6 & -163.2 \\
\hline & $\mathbf{1}+\mathbf{2 b} \rightarrow \mathbf{L M}_{\mathbf{D}}$ & -1.3 & 26.8 & -94.1 & & & \\
\hline & $1+2 \mathbf{b} \rightarrow \mathbf{T S}_{\mathbf{D}}$ & 154.8 & 205.9 & -171.1 & 152.7 & 205.0 & -174.9 \\
\hline & $1+2 b \rightarrow 8 b$ & 136.0 & 186.6 & -169.5 & 128.9 & 179.5 & -169.9 \\
\hline \multirow[t]{9}{*}{$2 c$} & $\mathbf{1}+\mathbf{2 c} \rightarrow \mathbf{L M}_{\mathbf{A}}$ & -5.0 & 30.1 & -118.4 & -5.9 & 19.7 & -85.4 \\
\hline & $1+2 c \rightarrow \mathbf{T S}_{\mathrm{A}}$ & 37.7 & 88.3 & -169.5 & 38.1 & 87.9 & -167.4 \\
\hline & $1+2 c \rightarrow 3 c$ & -231.0 & -172.8 & -194.6 & -231.8 & -172.4 & -199.6 \\
\hline & $1+2 \mathrm{c} \rightarrow \mathbf{T S}_{\mathbf{B}}$ & 33.5 & 82.4 & -164.4 & 28.5 & 77.0 & -164.0 \\
\hline & $1+2 c \rightarrow 3 c$ & -233.5 & -176.1 & -192.5 & -238.1 & -180.3 & -193.7 \\
\hline & $1+2 c \rightarrow \mathbf{T S}_{\mathbf{C}}$ & 63.6 & 108.4 & -151.0 & 50.6 & 95.8 & -151.9 \\
\hline & $1+2 c \rightarrow 7 c$ & -9.2 & 41.0 & -168.6 & -17.2 & 32.6 & -166.9 \\
\hline & $1+2 \mathrm{c} \rightarrow \mathrm{TS}_{\mathbf{D}}$ & 109.2 & 161.9 & -176.6 & 97.9 & 150.6 & -177.8 \\
\hline & $1+2 c \rightarrow 8 c$ & 66.9 & 115.9 & -164.8 & 59.4 & 107.9 & -162.3 \\
\hline
\end{tabular}


Table 4 Eyring parameters for reactions between nitroacetylene (1) and benzonitrile $N$-oxide (2a) in toluene according to DFT calculations at B3LYP/6-31+G(d), B3LYP/6-311G(d), and B3LYP/6-311+G(d) theory levels

\begin{tabular}{|c|c|c|c|c|}
\hline Theory level & Transition & $\Delta H / \mathrm{kJ} \mathrm{mol}^{-1}$ & $\Delta G / \mathrm{kJ} \mathrm{mol}^{-1}$ & $\Delta S / \mathrm{J} \mathrm{mol}{ }^{-1} \mathrm{~K}^{-1}$ \\
\hline \multirow{6}{*}{ B3LYP/6-31+G(d) } & $\mathbf{1}+\mathbf{2 a} \rightarrow \mathbf{L} \mathbf{M}_{\mathbf{A}}$ & -10.0 & 18.0 & -93.3 \\
\hline & $\mathbf{1}+\mathbf{2 a} \rightarrow \mathbf{T S}_{\mathbf{A}}$ & 48.5 & 95.8 & -158.6 \\
\hline & $\mathbf{1}+\mathbf{2 a} \rightarrow \mathbf{3 a}$ & -333.5 & -270.7 & -211.7 \\
\hline & $\mathbf{1}+\mathbf{2} \mathbf{a} \rightarrow \mathbf{L M}_{\mathbf{B}}$ & -2.9 & 32.6 & -119.7 \\
\hline & $\mathbf{1}+\mathbf{2 a} \rightarrow \mathbf{T S}_{\mathbf{B}}$ & 53.1 & 102.5 & -165.3 \\
\hline & $1+2 a \rightarrow 4 a$ & -332.2 & -271.1 & -204.2 \\
\hline \multirow[t]{6}{*}{ B3LYP/6-311G(d) } & $\mathbf{1}+\mathbf{2 a} \rightarrow \mathbf{L M}_{\mathbf{A}}$ & -11.7 & 19.7 & -105.4 \\
\hline & $1+2 \mathrm{a} \rightarrow \mathrm{TS}_{\mathrm{A}}$ & 49.8 & 100.0 & -168.2 \\
\hline & $1+2 a \rightarrow 3 a$ & -319.7 & -256.5 & -211.3 \\
\hline & $\mathbf{1}+\mathbf{2 a} \rightarrow \mathbf{L M}_{\mathbf{B}}$ & -7.1 & 26.8 & -112.5 \\
\hline & $\mathbf{1}+\mathbf{2 a} \rightarrow \mathbf{T S}_{\mathbf{B}}$ & 55.6 & 104.6 & -164.8 \\
\hline & $1+2 a \rightarrow 4 a$ & -318.4 & -257.7 & -204.2 \\
\hline \multirow[t]{6}{*}{ B3LYP/6-311+G(d) } & $\mathbf{1}+\mathbf{2 a} \rightarrow \mathbf{L} \mathbf{M}_{\mathbf{A}}$ & -10.0 & 17.6 & -92.0 \\
\hline & $\mathbf{1}+\mathbf{2 a} \rightarrow \mathbf{T S}_{\mathbf{A}}$ & 53.6 & 99.2 & -154.0 \\
\hline & $\mathbf{1}+\mathbf{2 a} \rightarrow \mathbf{3 a}$ & -310.9 & -248.5 & -209.2 \\
\hline & $\mathbf{1}+\mathbf{2 a} \rightarrow \mathbf{L} \mathbf{M}_{\mathbf{B}}$ & -0.8 & 26.8 & -92.5 \\
\hline & $\mathbf{1}+\mathbf{2 a} \rightarrow \mathbf{T S}_{\mathbf{B}}$ & 59.0 & 107.5 & -163.6 \\
\hline & $1+2 a \rightarrow 4 a$ & -309.6 & -248.1 & -205.4 \\
\hline
\end{tabular}

$\mu \approx\left(E_{\mathrm{HOMO}}+E_{\mathrm{LUMO}}\right) / 2 \quad \eta \approx E_{\mathrm{LUMO}}-E_{\mathrm{HOMO}}$.

Next, the values of $\mu$ and $\eta$ were then used for the calculation of global electrophilicity $(\omega)[16,17]$ according to the formula:

$\omega=\mu^{2} / 2 \eta$

and the global nucleophilicity $(N)$ [18] of TACs can be expressed in terms of equation:

$N=E_{\mathrm{HOMO}}(\mathrm{TAC})-E_{\mathrm{HOMO}}$ (tetracyanoethene)

The local electrophilicity $\left(\omega_{\mathrm{k}}\right)$ [19] condensed to atom $\mathrm{k}$ was calculated by projecting the index $\omega$ onto any reaction centre $\mathrm{k}$ in the molecule by using Parr function $\mathrm{P}_{\mathrm{k}}^{+}$[20]:

$\omega_{\mathrm{k}}=\mathrm{P}_{\mathrm{k}}^{+} \cdot \omega$.

The local nucleophilicity $\left(N_{\mathrm{k}}\right)$ [21] condensed to atom $\mathrm{k}$ was calculated using global nucleophilicity $N$ and Parr function $\mathrm{P}_{\mathrm{k}}^{-}$[20] according to the formula:

$N_{\mathrm{k}}=\mathrm{P}_{\mathrm{k}}^{-} \cdot N$.

Reactivity indexes calculated on this way are collected in Table 1.

For the simulation of the reaction paths hybrid functional B3LYP with the 6-31G(d), basis set included in the GAUSSIAN 09 package [22] was used. It was found previously that the $\mathrm{B} 3 \mathrm{LYP} / 6-31 \mathrm{G}(\mathrm{d})$ calculations illustrate well the structure of TSs in polar $[2+3]$ cycloadditions involving conjugated nitroalkenes [14, 23, 24]. The critical points on reaction paths were localized in an analogous manner as in the case of the previously analysed $[2+3]$ cycloadditions of (Z)-C,N-diphenylnitrone with gem-dinitroethene [14]. In particular, for structure optimization of the reactants and the reaction products the Berny algorithm was applied. First-order saddle points were localized using the QST2 procedure. The TSs were verified by diagonalization of the Hessian matrix and by analysis of the intrinsic reaction coordinates (IRC). In addition, similar simulations using more advanced B3LYP/6-31+G(d), B3LYP/6-311G(d), as well as B3LYP/6-311+G(d) theoretical levels were performed.

All calculations were carried out for the simulated presence of toluene or nitromethane as the reaction medium. For this purpose PCM model [25] was used. For optimized structures the thermochemical data for the temperature $T=298 \mathrm{~K}$ and pressure $p=1$ atm were computed using vibrational analysis data. Global electron density transfer (GEDT) [26] was calculated according to the formula:

$G E D T=-\Sigma q_{\mathrm{A}}$

where $q_{\mathrm{A}}$ is the net Mulliken charge and the sum is taken over all the atoms of dipolarophile.

Indexes of $\sigma$-bonds development $(l)$ were calculated according to formula [27]: 
$l_{\mathrm{A}-\mathrm{B}}=1-\frac{r_{\mathrm{A}-\mathrm{B}}^{\mathrm{TS}}-r_{\mathrm{A}-\mathrm{B}}^{\mathrm{P}}}{r_{\mathrm{A}-\mathrm{B}}^{\mathrm{P}}}$,

where $r_{\mathrm{A}-\mathrm{B}}^{\mathrm{TS}}$ is the distance between the reaction centres $\mathrm{A}$ and $\mathrm{B}$ at the TS and $r_{\mathrm{A}-\mathrm{B}}^{\mathrm{P}}$ is the same distance at the corresponding product.

The kinetic parameters as well as essential properties of critical structures are displayed in Tables 2, 3, 4 .

Acknowledgments The generous allocation of computing time by the regional computer centre "Cyfronet" in Cracow (Grant No. MNiSW/Zeus_lokalnie/PK/009/2013), and financial support from the Polish State Committee (Grant No. C-2/33/2014/DS) are gratefully acknowledged.

Open Access This article is distributed under the terms of the Creative Commons Attribution License which permits any use, distribution, and reproduction in any medium, provided the original author(s) and the source are credited.

\section{References}

1. Rall KB, Vil'davskaya AI, Petrov AA (1975) Russ Chem Rev 44:373

2. Zhang O-Xi, Eaton PE, Steele I, Gilardib R (2002) Synthesis 2002:2013

3. Benchouk W, Mekelleche SM, Silvi B, Aurell MJ, Domingo LR (2011) J Phys Org Chem 24:611

4. Jawalekar AM, Reubsaet E, Rutjes FPJT, van Delft FL (2011) Chem Commun 47:3198

5. Domingo LR, Chamorro E, Pérez P (2009) Eur J Org Chem 2009:3036

6. Domingo LR, Aurell MJ, Perez P (2014) Tetrahedron 70:4519

7. Bekhradnia AR, Arshadi S, Siadati SA (2014) Chem Papers 68:283

8. Lopez SA, Munk ME, Houk KN (2013) J Org Chem 78:1576

9. Goulioukina NS, Makukhin NN, Beletskaya IP (2011) Tetrahedron 67:9535

10. Kurpet M, Jędrysiak R, Suwiński J (2013) Chem Heterocyclic Compd 48:1737
11. Larina L, Lopyrev V (2009) Nitroazoles: Synthesis, Structure and Applications. Springer, New York

12. Boyer JH (1986) Nitroazoles: the C-nitro derivatives of fivemembered $\mathrm{N}$ - and $\mathrm{N}$, O-heterocycles. VCH, Weinheim

13. Khlebnikov AF, Koneva AS, Virtseva AA, Yufit DS, Mlostoń G, Heimgartner H (2014) Helv Chim Acta 97:453

14. Jasiński R (2013) Tetrahedron 69:927

15. Jasiński R, Kwiatkowska M, Barański A (2007) Wiad Chem 61:485

16. Parr RG, von Szentpaly L, Liu LS (1999) J Am Chem Soc 121:1922

17. Domingo LR, Aurell MJ, Perez P, Contreras R (2002) Tetrahedron 58:4417

18. Domingo LR, Chamorro E, Perez P (2008) J Org Chem 73:4615

19. Domingo LR, Aurell MJ, Perez P, Contreras R (2002) J Phys Chem A 106:6871

20. Domingo LR, Perez P, Saez JA (2013) RSC Adv 3:1486

21. Perez P, Domingo LR, Duque-Norena M, Chamorro E (2009) J Mol Struct (TheoChem) 895:86

22. Frisch MJ, Trucks GW, Schlegel HB, Scuseria GE, Robb MA, Cheeseman JR, Scalmani G, Barone V, Mennucci B, Petersson GA, Nakatsuji H, Caricato M, Li X, Hratchian HP, Izmaylov AF, Bloino J, Zheng G, Sonnenberg JL, Hada M, Ehara M, Toyota K, Fukuda R, Hasegawa J, Ishida M, Nakajima T, Honda Y, Kitao O, Nakai H, Vreven T, Montgomery JA Jr, Peralta JE, Ogliaro F, Bearpark M, Heyd JJ, Brothers E, Kudin KN, Staroverov VN, Kobayashi R, Normand J, Raghavachari K, Rendell A, Burant JC, Iyengar SS, Tomasi J, Cossi M, Rega N, Millam NJ, Klene M, Knox JE, Cross JB, Bakken V, Adamo C, Jaramillo J, Gomperts R, Stratmann RE, Yazyev O, Austin AJ, Cammi R, Pomelli C, Ochterski JW, Martin RL, Morokuma K, Zakrzewski VG, Voth GA, Salvador P, Dannenberg JJ, Dapprich S, Daniels AD, Farkas O, Foresman JB, Ortiz JV, Cioslowski J, Fox DJ (2009) Gaussian 09, Revision A.01. Gaussian, Inc, Wallingford

23. Jasiński R, Ziółkowska M, Demchuk OM, Maziarka A (2014) Central Eur J Chem 12:586

24. Jasiński R (2009) Coll Czech Chem Commun 74:1341

25. Cossi M, Rega N, Scalmani G, Barone V (2003) J Comp Chem 24:669

26. Domingo LR (2014) RSC Adv 4:32415

27. Jasiński R, Kwiatkowska M, Baranski R (2009) J Mol Struct (TheoChem) 910:80 